\title{
Mechanisms of Action of Peripherally Administered Cholecystokinin Octapeptide on Brain Stem Neurons in the Rat
}

\author{
Helen E. Raybould, ${ }^{\mathrm{a}}$ R. J. Gayton, and G. J. Dockray \\ MRC Secretory Control Group, Physiological Laboratory, University of Liverpool, Liverpool, UK
}

\begin{abstract}
We have investigated the pathway and the mechanism by which cholecystokinin octapeptide (CCK-8), given systemically, may influence the discharge of brain stem neurons that have an input from the stomach. Extracellular recordings were made from neurons in the nucleus of the solitary tract (NTS), where vagal afferents terminate, and from neighboring regions of the dorsal medial medulla. Gastric distension and CCK-8 injected intra-aortically close to the stomach evoked either excitatory or inhibitory responses that were abolished by cervical vagal section. In animals from which the celiac/superior mesenteric ganglia were removed, or the gastric antrum resected 2 weeks earlier, responses to gastric distension and CCK-8 were maintained. The effects of CCK-8 are unlikely to be secondary to changes in smooth muscle tone because CCK- 8 decreased pressure in the body of the stomach, while distension increased it. Moreover, intravenous noradrenaline and vasoactive intestinal peptide had effects similar to CCK-8 on intragastric pressure, but evoked different patterns of responses from brain stem neurons. The results are consistent with the idea that CCK-8 acts directly on vagal mechanoreceptive endings in the gastric corpus wall. It is well known that peripheral administration of CCK-8 influences short-term regulation of food intake. The effects described here may reflect the pathway by which peripheral CCK influences CNS function.
\end{abstract}

Peripheral administration of cholecystokinin (CCK) evokes a number of behavioral effects, including satiety (Gibbs et al., 1973, 1976), decrease in exploratory behavior (Crawley et al., 1981), sedation (Zetler, 1981), and analgesia (Zetler, 1980). Iontophoretic application of CCK excites neurons in many CNS regions, including the hippocampus, substantia nigra, brain stem, and spinal cord (Oomura et al., 1978; Dodd and Kelly, 1981; Jeftinija et al., 1981; Ewart and Wingate, 1983; Morin et al., 1983; Hommer et al., 1985). However, there is evidence that CCK given intravenously (i.v.) or intraperitoneally (i.p.) influences the CNS not by a direct action on central neurons, but indirectly via actions at a peripheral site. Thus, section of the gastric branch of the vagus and lesion of the nucleus of the solitary tract (NTS) abolished the effects of CCK on satiety and exploratory behavior (Crawley et al., 1981; Smith et al., 1981; Lorenz and Goldman, 1982; Morley et al., 1982; Crawley and

Received Aug. 24, 1987; revised Dec. 18, 1987; accepted Dec. 21, 1987.

Correspondence should be addressed to H. E. Raybould, Ph.D., CURE/VA Wadsworth Medical Center, Building 115, Room 203, Los Angeles, CA 90073.

a Present address: Center for Ulcer Research and Education, VA Wadsworth Medical Center, Los Angeles, CA 90073.

Copyright $\subset 1988$ Society for Neuroscience $0270-6474 / 88 / 083018-07 \$ 02.00 / 0$
Schwaber, 1984). Similarly, the sensory neurotoxin capsaicin blocks the satiety effect of CCK (Ritter and Ladenheim, 1985).

In a previous study, we reported that brain stem neurons receiving an input from the stomach responded to intravenous administration of cholecystokinin octapeptide (CCK-8) (Raybould et al., 1985). The changes in neuronal discharge evoked by CCK- 8 and gastric distension were in the same direction, suggesting that the 2 stimuli act through a common neural pathway. Moreover, CCK-8 was more potent in eliciting changes in neuronal discharge when administered intra-aortically close to the stomach, compared to intravenous injection, suggesting that it acts within the splanchnic bed. In the present study, we have sought to establish the pathway and mechanisms by which CCK-8 influences the discharge of brain stem neurons. The pathway by which gastric distension and CCK-8 influence the discharge of brain stem neurons was studied by examining responses before and after acute bilateral cervical vagotomy, and in animals from which the celiac/superior mesenteric ganglia were removed. The mechanism by which CCK-8 may act in the periphery was also investigated; experiments were performed in rats from which the gastric antrum was removed. In addition, the possibility that alterations in neuronal discharge were due to changes in gastric smooth muscle tone produced by CCK- 8 was investigated by a simultaneous recording of intragastric pressure and by studying the action of vasoactive intestinal peptide (VIP) and noradrenaline, which, like CCK-8, decrease intragastric pressure (Raybould et al., 1987). The results described here are consistent with the idea that CCK-8 acts directly on vagal afferent mechanorcceptive endings in the gastric wall.

\section{Materials and Methods}

Experiments were performed on male Sprague-Dawley rats (200-350 $\mathrm{gm} ; n=55)$ anesthetized with urethane $(1.25 \mathrm{gm} / \mathrm{kg}$, i.p.). The animals were fasted overnight before experiments but allowed water ad libitum. A cannula was placed in the trachea to ensure a clear airway.

Gastric distension was produced by instillation of $0.9 \%$ saline via a catheter placed in the body of the stomach through the duodenum and secured at the pylorus. Pressure in the body of the stomach was rccorded using a catheter passed into the stomach through the esophagus, connected to a pressure transducer (Statham P23ID), and displayed on a 2-channel chart recorder. Neurons responding to gastric distension were identified by the response to $2 \mathrm{ml}$ saline instilled into the stomach over 10-20 sec; distension was maintained for 1-5 min. Intravenous injections were made using a catheter placed in the external jugular vein. Intra-aortic (i.a.) injections close to the splanchnic vascular bed were made using a catheter inserted into the carotid artery passed down the aorta until the tip was at the junction with the celiac artery. Peptides were dissolved in $0.1 \%$ bovine serum albumin in $0.9 \%$ saline. Injections were made as a $0.1 \mathrm{ml}$ bolus flushed in with a $0.2 \mathrm{ml} 0.9 \%$ saline as follows: CCK-8 (100 pmol to $10 \mathrm{nmol})$, VIP (100 pmol), and noradrenaline $(100 \mathrm{ng}$ or $1 \mu \mathrm{g})$. Synthetic sulfated CCK-8 was a generous gift of 

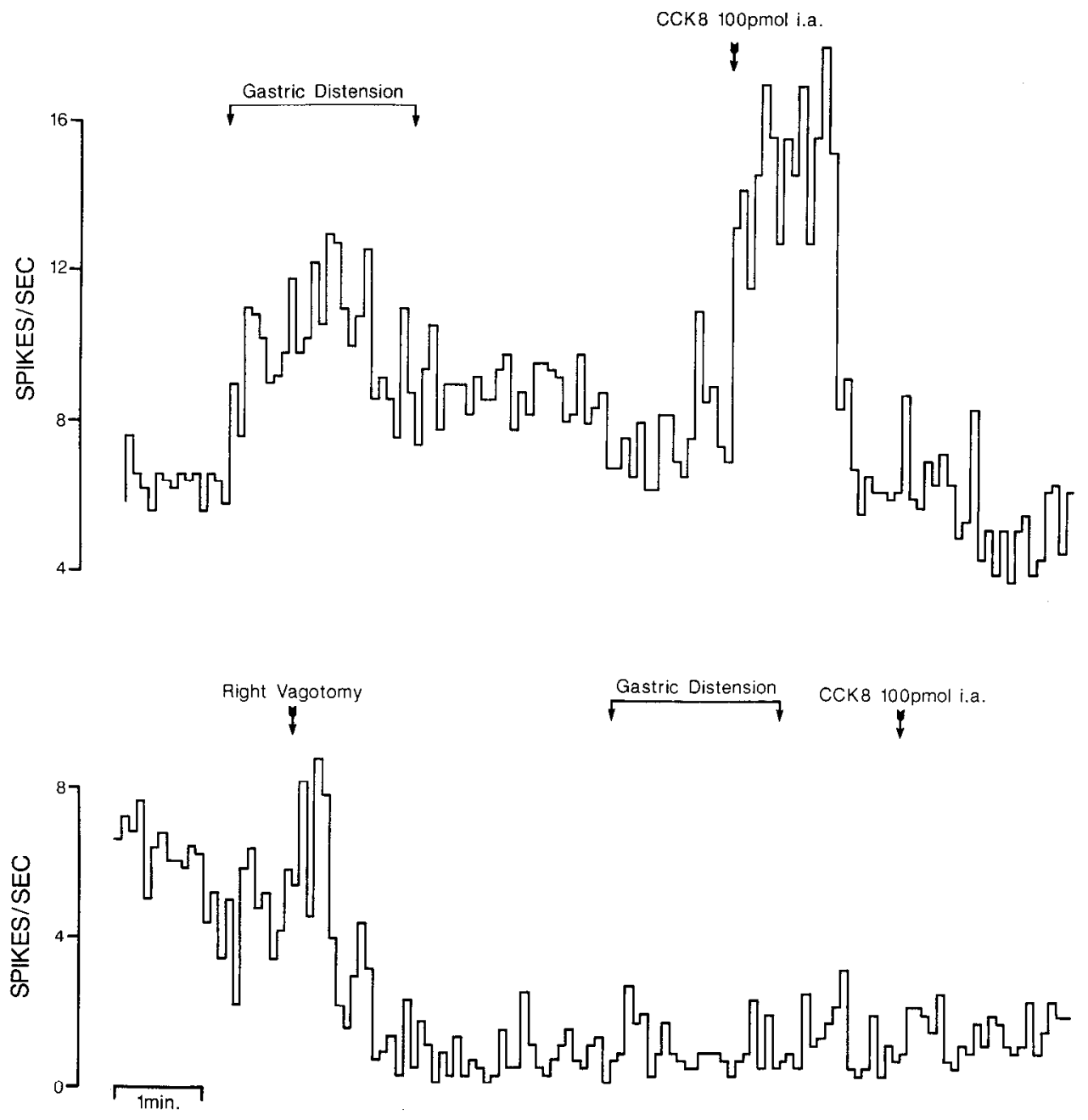

Figure 1. Extracellular recording of neuronal activity in the left NTS from urethane-anesthetized rat. Gastric distension was produced by instillation of $2 \mathrm{ml}$ of $0.9 \%$ saline over $10-20 \mathrm{sec}$. Intra-aortic injections close to the splanchnic vascular bed were made using a catheter in the carotid artery, passed down the aorta until the tip lay at the junction with the celiac artery. The discharge of this neuron is increased by both gastric distension and intra-aortic (i.a.) injection of $100 \mathrm{pmol}$ of CCK-8. Responses to both stimuli were abolished by contralateral vagotomy, which also decreased spontaneous discharge.

Dr. B. Penke and pure natural porcine VIP was generously donated by Professor V. Mutt.

Units responding to gastric distension were identified in intact rats before and after acute vagotomy $(n=8)$ and in rats from which the celiac/superior mesenteric ganglia were removed $(n=9)$ or the gastric antrum resected $(n=3)$. Acute cervical vagotomy was performed by placing silk snares loosely around both vagi; vagotomy was then achieved during the recording of neuronal activity by avulsion.

Experiments involving pyloric antrectomy or celiac/superior mesenteric ganglionectomy were performed as follows 2 weeks prior to electrophysiological recording: Rats were anesthetized with halothane (1-2\%). Using full aseptic precautions, the gastric antrum, pylorus, and first $0.5 \mathrm{~cm}$ of the duodenum were removed. The duodenal stump and the cut edges of the stomach were sutured, and a loop of distal duodenum was anastomosed to the gastric corpus. Alternatively, the rats were anesthetized with sodium pentobarbitone $(60 \mathrm{mg} / \mathrm{kg}$, i.p.; May and Baker, UK), and the celiac and superior mesenteric ganglia carefully extirpated.

Electrophysiological recordings were made on rats placed in a stereotaxic frame with the head in a nose-down position. The obex was exposed by resecting the neck musculature and removal of part of the occipital plate. Extracellular recordings of single-ncuron activity wcrc made through the central barrel of glass multibarreled microelectrodes. The obex was used as the zero reference point and the coordinates 0.5 $\mathrm{mm}$ rostrocaudal and $0.75 \mathrm{~mm}$ lateral to the obex used to position the electrodes in the dorsal vagal complex (DVC). The position of the electrode tip was marked by iontophoretic application of pontamine sky blue and verified using the atlas of Palkovits and Jacobowitz (1974).

Analysis of data. The output from the preamplifier was displayed on an oscilloscope and the discriminator levels on the spike processor (D130 Digitimer) adjusted according to spike height. The number of impulses was counted over bin widths of $1-5 \mathrm{sec}$ and displayed on a chart recorder beside the intragastric pressure. The level of activity of neurons, both spontaneous and evoked, was calculated for a $1 \mathrm{~min}$ period and expressed as the number of spikes per second. In some experiments, the data were stored on disk (BBC Microcomputer) and later retrieved, and calculations performed for the required portions of the trace.

\section{Results}

In keeping with the previous report (Raybould et al., 1985), the discharge of spontaneously active neurons in the dorsal medial medulla was either increased by gastric distension, decreased by gastric distension, or did not change. For all 3 groups of cells the spontaneous activity varied from 0 to $16 \mathrm{~Hz}$, with $83 \%$ of neurons below $10 \mathrm{~Hz}$. A $2 \mathrm{ml}$ inflation of the stomach, or injection of CCK-8 (100 pmol, i.a.) resulted in a 1.5-10 times increase in firing rate of excitatory neurons and a $25-100 \%$ decrease in the firing of inhibitory neurons. For the majority of neurons whose discharge was influenced by gastric distension, the discharge remained elevated or depressed for the duration of the gastric distension (Figs. 1, 2). The response of some neurons, however, did show some adaptation to a maintained gastric distension (Fig. 3).

Injection of CCK-8, i.a., close to the stomach increased the discharge of 29 of 29 neurons excited by gastric distension and decreased the discharge of 29 of 29 neurons inhibited by gastric distension. A direct comparison of the response to intravenous and intra-aortic injections of CCK-8 was made on 15 neurons 

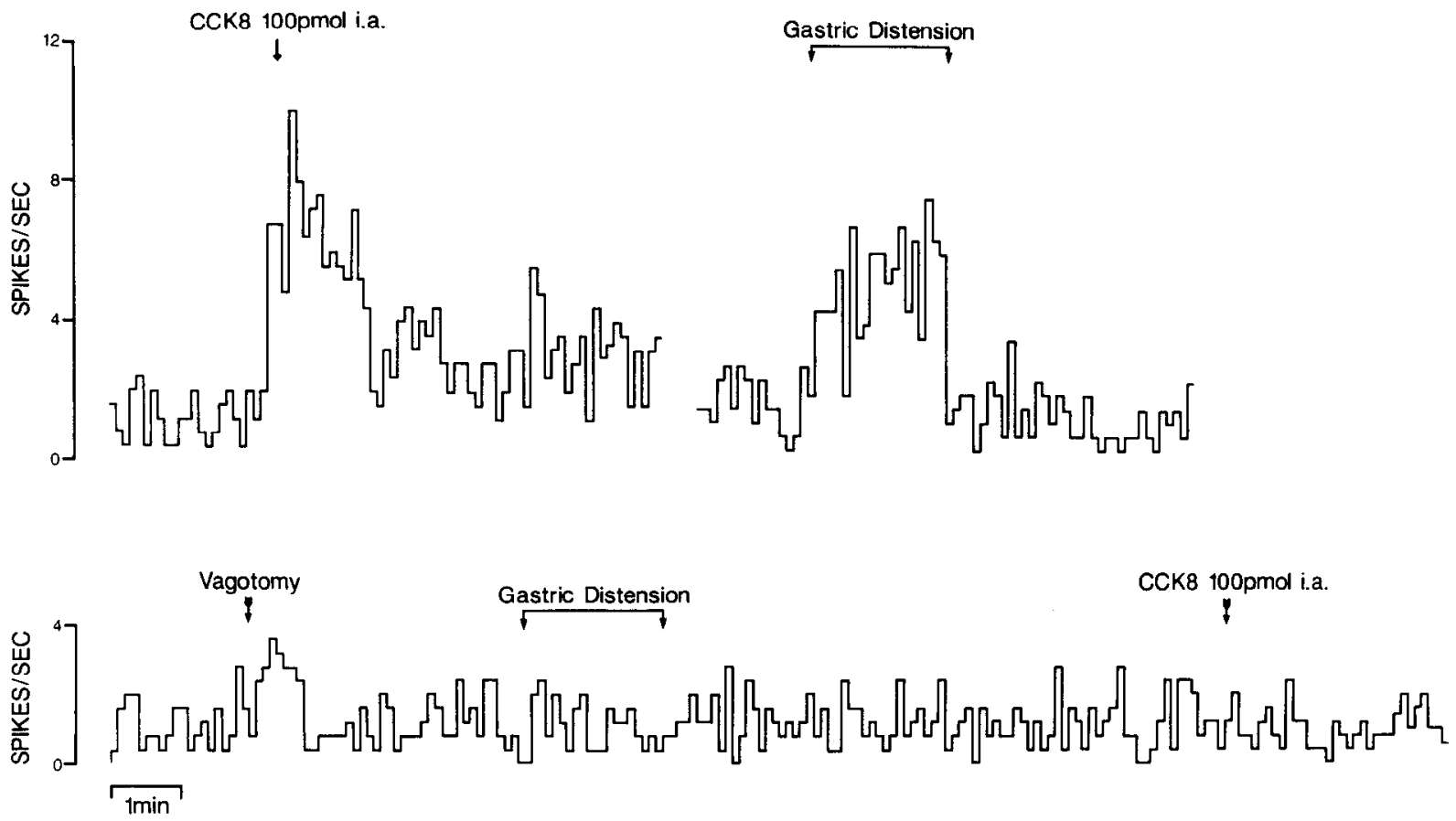

Figure 2. The spontaneous discharge of this neuron was increased by gastric distension and i.a. injection of CCK-8. Following bilateral vagotomy, the response to both stimuli was abolished. The second parts of the upper and the lower trace are continuous.

( 8 excitatory and 7 inhibitory). In all cases, 100 pmol, i.a., gave a long-lasting response, and the same dose, i.v., had no effect or produced small, transient responses.

Neurons responding to gastric distension were located throughout the dorsal vagal complex, in particular the medial commissural nucleus, the medial and caudal portion of the NTS, and the dorsal vagal motor nucleus (DVMN). A few neurons were located in the reticular formation ventral to the NTS and DVMN.

\section{Acute cervical vagotomy}

The effect of unilateral vagotomy was tested on changes in neuronal discharge in response to gastric distension and CCK-8 of 6 excitatory neurons, all located in the left NTS. Right (contralateral) vagotomy abolished the response to gastric distension and CCK-8 of only one neuron (Fig. 1). Subsequent section of the ipsilateral vagus abolished responses to gastric distension and CCK -8 of the remaining neurons ( $n=5$ ) (Fig. 2). Bilateral vagotomy abolished the responses to gastric distension and CCK- 8 of the 2 inhibitory neurons tested. The spontaneous discharge of both excitatory and inhibitory neurons was de-

Table 1. Effect of CCK-8 (100 pmol, i.a.), VIP (100 pmol, i.a.), and noradrenaline (100 $\mathrm{pg}$, i.a.) on brain stem neurons responding to gastric distension

\begin{tabular}{lccl} 
Response to & \multicolumn{3}{l}{$\begin{array}{l}\text { Responses concordant with } \\
\text { gastric distension }\end{array}$} \\
\cline { 2 - 4 } $\begin{array}{llll}\text { gastric } \\
\text { distension }\end{array}$ & CCK-8 & $\begin{array}{l}\text { Noradren- } \\
\text { aline }\end{array}$ & VIP \\
\hline Excited & $9 / 9$ & $3 / 7$ & $3 / 9$ \\
Inhibited & $11 / 11$ & $3 / 4$ & $2 / 11$ \\
No effect & $9 / 9$ & $4 / 9$ & $4 / 9$ \\
\hline
\end{tabular}

creased by vagotomy; the spontaneous discharge of 3 neurons decreased to zero 20-30 min after vagotomy.

\section{Effect of antrectomy and celiac ganglionectomy}

Recordings were made from 4 excitatory, 4 inhibitory, and 8 neurons not responding to gastric distension in 3 rats in which the gastric antrum was resected. The responses of the neurons to CCK-8 (1-5 nmol, i.v.) were indistinguishable from those in intacts rats. In 9 rats from which the celiac/superior mesenteric ganglia were removed, recordings were made from 4 excitatory and 5 inhibitory neurons; the response to gastric distension and CCK-8 (100 pmol, i.a.) were indistinguishable from those obtained in intact rats (Fig. 3).

\section{Effect of noradrenaline and VIP}

Intravenous injection of CCK-8 (100 pmol), VIP (100 pmol), and noradrenaline (100 $\mathrm{ng}$ ) rapidly decreased intragastric pressure and inhibited phasic contractions of the body of the stomach (Fig. 4). The effects of CCK-8 on neurons located in the dorsal medial medulla were compared to those of VIP on 9 excitatory, 11 inhibitory, and 9 neurons unaffected by gastric distension, and with those of noradrenaline on 7 excitatory, 4 inhibitory, and 9 neurons unaffected by gastric distension. Examples of the responses obtained are shown in Figures 3, 5, and 6 , and summarized in Table 1 . It is apparent that while VIP and noradrenaline influenced the discharge of some medullary neurons, the patterns of response were different from that evoked by CCK-8, and, in particular, the concordance of effects with gastric distension were not seen. It is also worth noting that both VIP and noradrenaline influenced the discharge of neurons that were unaffected by gastric distension and CCK-8.

\section{Discussion}

The data presented here provide evidence that CCK- 8 influences the discharge of brain stem neurons with a gastric input by an 


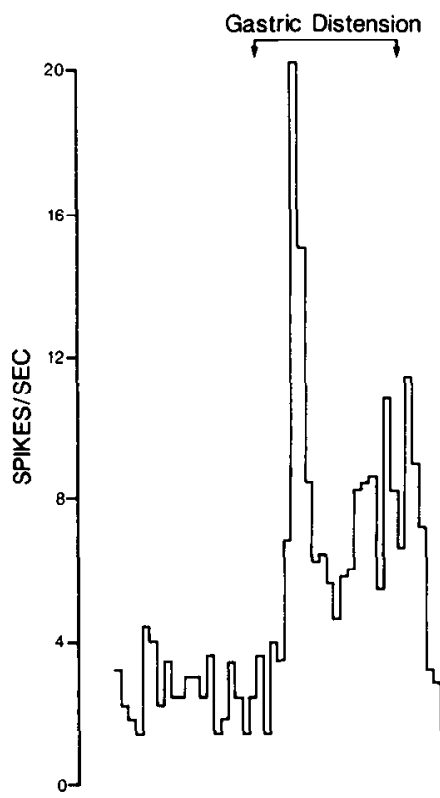

If]

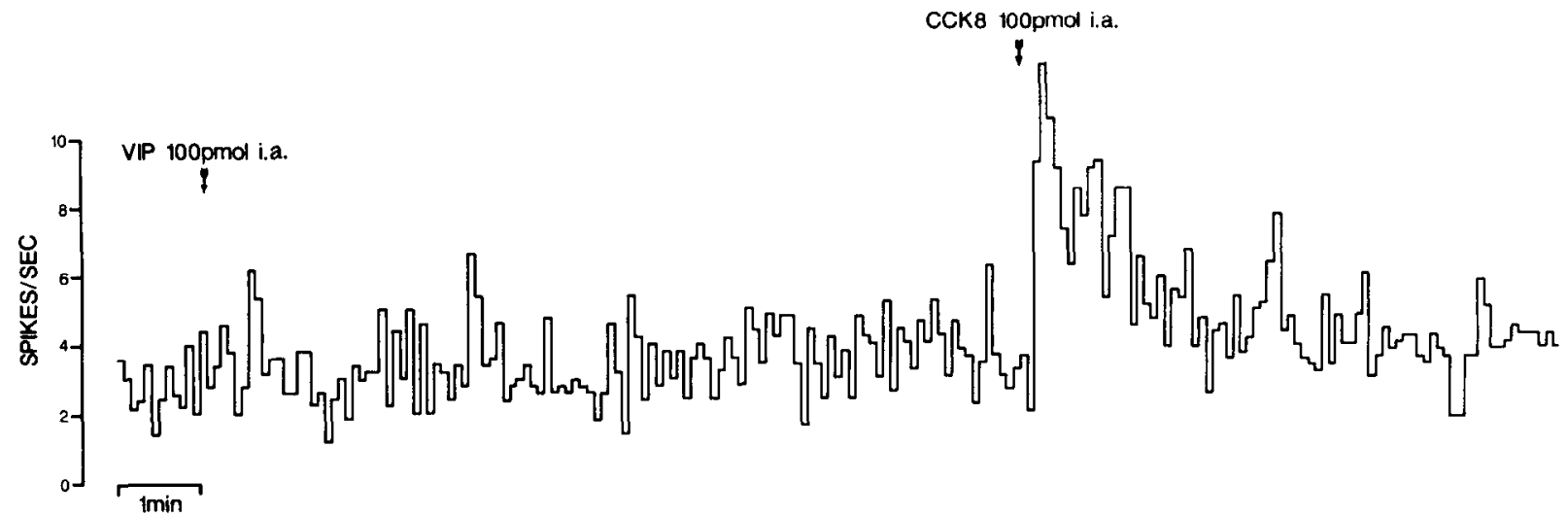

Figure 3. Extracellular recording of neuronal activity in the dorsal medial medulla of a urethane-anesthetized rat from which the celiac/superior mesenteric ganglia were removed 2 weeks previously under pentobarbitone anesthesia. Response of the neuron to CCK- 8 and gastric distension are indistinguishable from that in intact rats (cf. Figs. 1 and 2). The discharge of this neuron was unaffected by injection of noradrenaline (NA) or vasoactive intestinal peptide $(V I P)$. Upper and lower traces are continuous.

action in the periphery, probably the distal stomach, that is mediated by the vagus nerve. The present results also suggest that the action of CCK-8 is distinct from that of noradrenaline or VIP (which produce similar effects on gastric motility). Taken together, the results are consistent with the idea that CCK-8 acts on the vagal afferent pathway by a direct action on mechanoreceptive endings in the gastric wall.

Dorsal medial medullary neurons excited or inhibited by gastric distension have previously been identified in rat (Ewart and Wingate, 1983; Rogers and Hermann, 1985), cat (Barber and
Burks, 1983), and sheep (Harding and Leek, 1972, 1973). These observations are also readily related to earlier recordings of vagal efferent fiber discharge, which demonstrated both types of response to gastric distension (Davison and Grundy, 1978). The response of brain stem neurons to gastric distension in the present study suggests that they receive an input from gastric "in series" tension receptors previously characterized in single-fiber recordings of vagal afferent activity in several species (Paintal, 1954; Iggo, 1957; Leek, 1969; Clarke and Davison, 1975; Andrews et al., 1980). However, recordings from single vagal af-
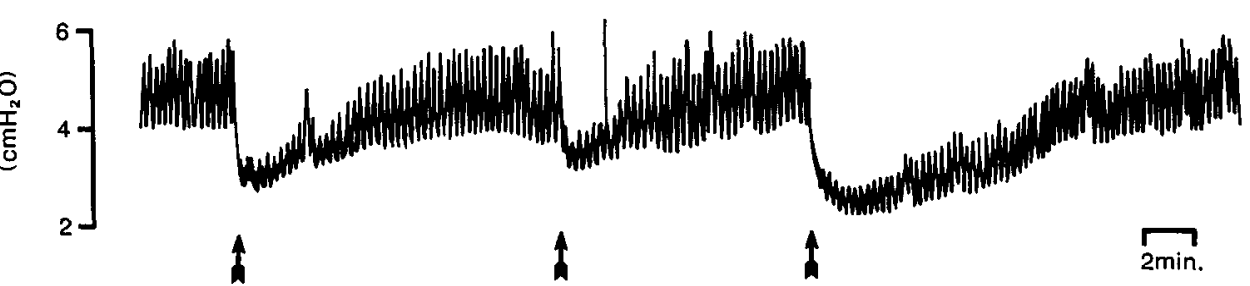

NA 100ng i.v.

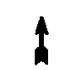

CCK8 100pmol i.v.
VIP 100pmol i.v.
Figure 4. Effect of intravenous administration of CCK-8, noradrenaline $(N A)$, and vasoactive intestinal peptide $(V I P)$ on intragastric pressure in the gastric corpus of urethane-anesthetized rats. Intragastric pressure was recorded using a catheter passed into the stomach through the esophagus. Responses to all 3 consist of a rapid decrease in intragastric pressure and inhibition of phasic contractions. 


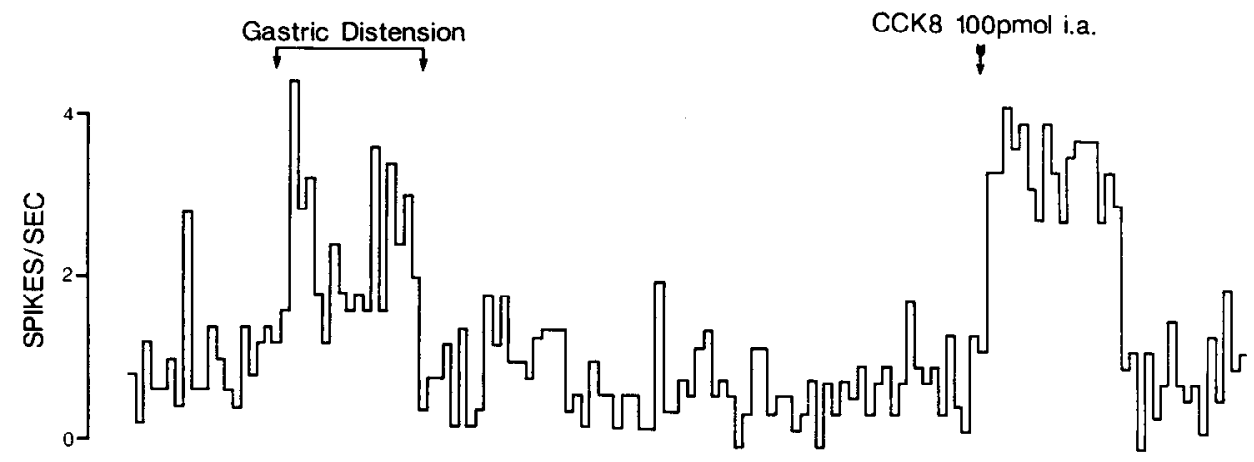

Figure 5. The spontaneous discharge of this neuron is excited by both gastric distension and CCK-8, i.a.; by contrast, intra-aortic injection of NA and VIP decrease the discharge of this neuron. Upper and lower traces are continuous.

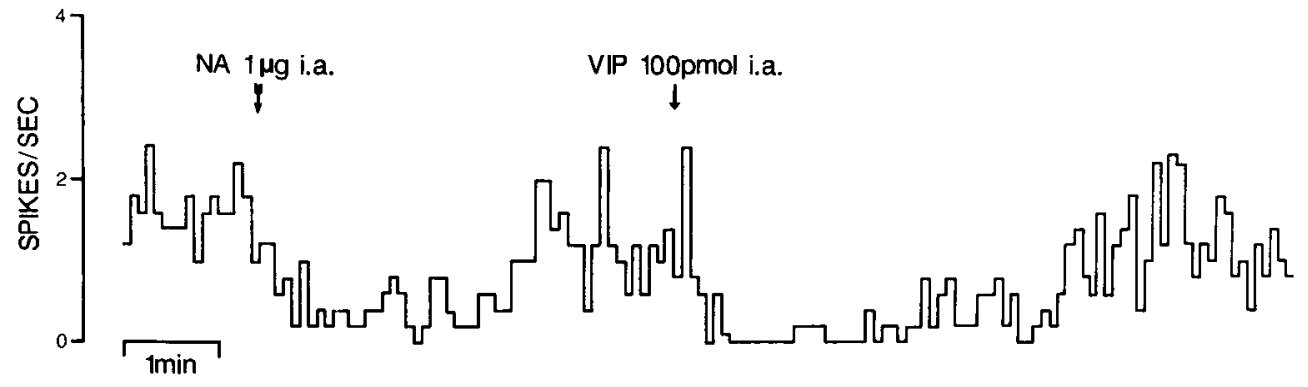

ferent fibers suggest that gastric distension produces only increases in fiber discharge. It is probable, then, that the brain stem neurons inhibited by gastric distension and CCK-8 reflect the activity of an inhibitory interneuron. We have been unable to identify differences between the distribution of neurons that are excited or inhibited by gastric distension. The neurons responding to distension were located in the dorsal vagal nucleus and the medial and caudal portion of the NTS, extending into the commissural nucleus caudal to the obex. Neuronal tracttracing experiments using transganglionically transported HRP have shown that these regions contain the central terminations of gastric vagal afferents (Kalia and Mesulam, 1980; Leslie et al., 1982; Scharoun et al., 1984; Shapiro and Miselis, 1985). It has also been demonstrated electrophysiologically that these regions contain neurons that receive an input from afferent fibers of the gastric vagus (Rogers and Hermann, 1985). In the present study, neurons responding to gastric distension were also located in the reticular formation ventral to the NTS. A small number of gastric vagal afferents have been shown anatomically to terminate in this region (Shapiro and Miselis, 1985). In the cat (Barber and Burks, 1983) and sheep (Harding and Leek, 1972), this region was also found to contain neurons that responded to gastric distension. The results from unilateral vagotomy demonstrate that neurons received an afferent input mainly from the ipsilateral vagus, although evidence was obtained for a contralateral input. Anatomical experiments have shown that there is a heavy ipsilateral projection and a weaker contralateral projection from gastric vagal afferents to the NTS (Leslie et al., 1982; Scharoun et al., 1984; Shapiro and Miselis, 1985).

Single-unit recordings of vagal afferent fiber discharge have shown that gastric mechanoreceptors innervate both the antrum and corpus (Paintal, 1954; Andrews et al., 1980). However, responses to gastric distension and CCK- 8 were maintained in rats from which the antrum was removed, suggesting that the response to CCK- 8 originates, at least in part, from the gastric corpus. Because the effects of CCK- 8 on gastric motility in the rat are in the opposite direction to those of gastric distension, it is unlikely that CCK-8 influences vagal afferents via changes in gastric smooth muscle tone. This is consistent with the results from single-fiber recordings that indicate that in the rat, CCK-8 acts on vagal afferents mediating gastric "in series" tension receptor discharge (Davison, 1986). It is also worth noting that CCK excited the discharge in hepatic and pancreatic vagal afferents (Niijima, 1981). In contrast, single-unit recordings from vagal afferent fibers of tension receptors in the sheep duodenum suggest that the effects of CCK-8 are secondary to changes in duodenal smooth muscle tone (Cottrell and Iggo, 1984). The CCK-induced fall in intragastric pressure in the rat is a reflex response dependent on both the vagal and splanchnic innervation to the stomach; the latter effect is mediated in part by noradrenaline (Raybould et al., 1987). One candidate for the mediation of vagal relaxation is VIP. We considered the possibility that release of either VIP or noradrenaline might directly mediate the effects of CCK-8 on brain stem neurons. Neither, however, was able to duplicate the effects of peripheral CCK-8 on brain stem neurons. Taken as a whole, the evidence is compatible, therefore, with the view that CCK-8 acts directly on vagal afferent endings in the gastric wall. In this context, it is noteworthy that CCK-binding sites have already been identified on subdiaphragmatic vagal fibers (Moran et al., 1987) and shown to be transported towards the periphery (Zarbin et al., 1981).

It is already known that gastric distension can initiate a variety of reflex changes in gastric motility and secretion, as well as produce behavioral effects. The proposal that gastric distension and CCK-8 activate a common neural pathway raises the possibility that CCK-8 might exert the same type of effect. There are at least 2 examples to suggest that this is indeed the case. First, it is well established that early in feeding, distension of the stomach initiates a reflex vago-vagal relaxation of the gastric wall that allows an increased volume, but maintains a constant 


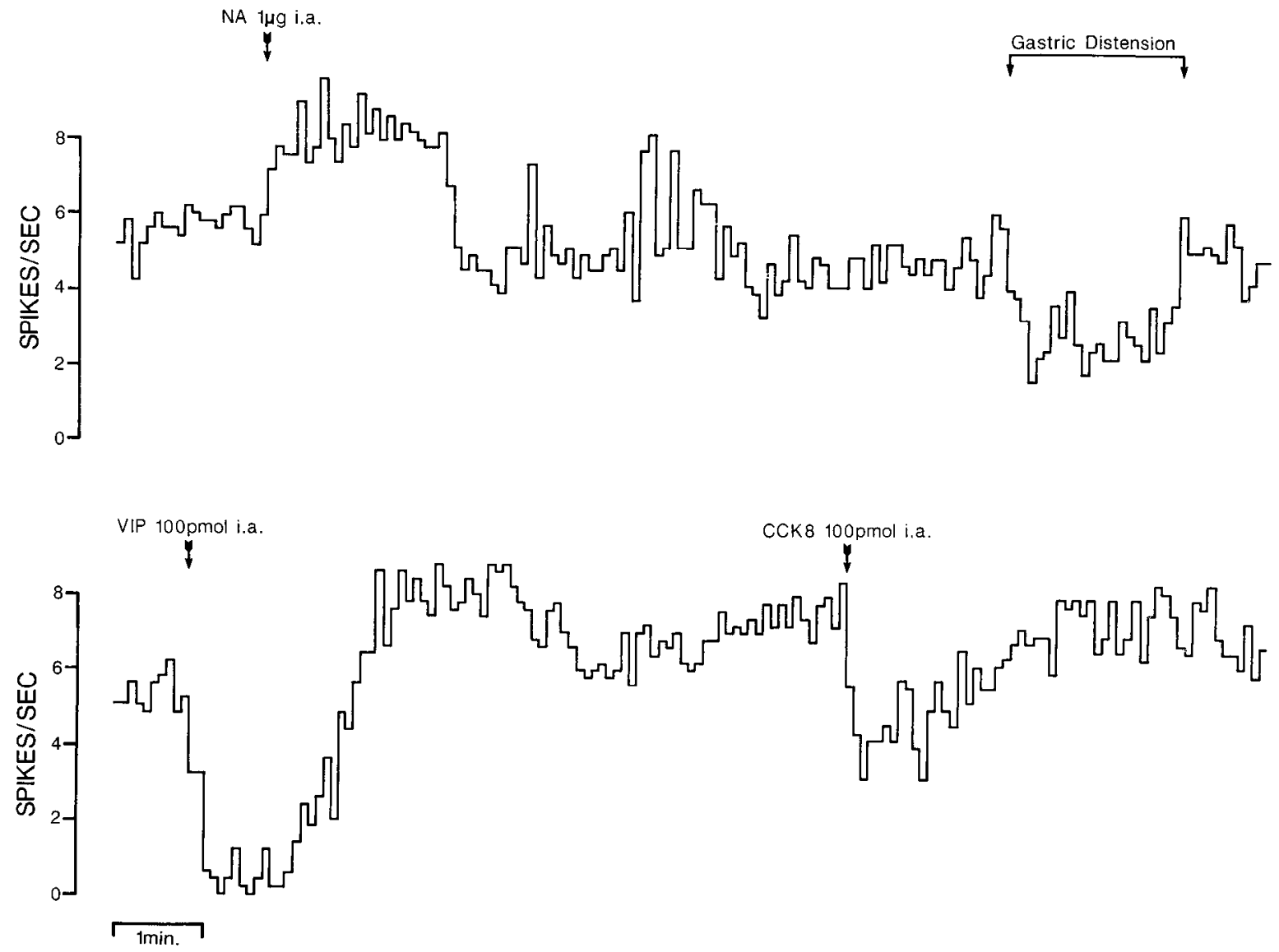

Figure 6. The spontaneous discharge of this neuron is inhibited by both gastric distension and CCK-8, i.a. The discharge is also inhibited by injection of VIP, but is excited by injection of NA. The upper and lower traces are continuous.

pressure (Wilbur et al., 1974). As already mentioned, CCK-8 is able to produce a similar reflex relaxation (Raybould et al., 1987). Second, gastric disterision inhibits food intake; in the rat, this is dependent on the integrity of the vagus nerve (Gonzalez and Deutsch, 1981). It is well known that peripheral administration of CCK inhibits feeding, not only in rats, where it was first shown, but also in several other species, including monkey (Gibbs et al., 1976; Falasco et al., 1979; Moran and McHugh, 1982) and man (Sturdevant and Goetz, 1976; Kisselif et al., 1979; Stacher et al., 1982). There is evidence, at least in the rat, that CCK exerts its action through a vagal afferent pathway (Crawley et al., 1981; Smith et al., 1981; Lorenz and Goldman, 1982; Morley et al., 1982; Crawley and Schwaber, 1984). Moreover, in the monkey there is direct evidence for an interaction between CCK and gastric distension in inhibition of feeding (Moran and McHugh, 1982). The present findings suggest a mechanism by which CCK and gastric distension are able to evoke similar behavioral and visceral effects.

\section{References}

Andrews, P. L. R., D. Grundy, and T. Scratcherd (1980) Vagal afferent discharge from mechanoreceptors in different regions of the ferret stomach. J. Physiol. (Lond.) 298: 513-524.

Barber, W. D., and T. F. Burks (1983) Brain stem responses to phasic gastric distension. Am. J. Physiol. 245: G242-G248.

Clarke, G. D., and J. S. Davison (1975) Tension receptors in the oesophagus and stomach of the rat. J. Physiol. (Lond.) 214: 41 P-42P.

Cottrell, D. F., and A. Iggo (1984) The response of duodenal tension receptors to cholecystokinin and some other drugs. J. Physiol. (Lond.) 354: $477-495$.

Crawley, J. N., and J. S. Schwaber (1984) Abolition of the behavioral effects of cholecystokinin following bilateral radio frequency lesions of the parvocellular subdivisions of the nucleus tractus solitarius. Brain Res. 295: 289-299.

Crawley, J. N., S. E. Hays, and S. M. Paul (1981) Vagotomy abolishes the inhibitory effects of cholecystokinin on rat exploratory behaviors. Eur. I. Pharmacol. 73: 370-380.

Davison, J. S. (1986) Response of vagal gastric mechanoreceptors to circulating cholecystokinin and adrenaline in the rat. Can. J. Physiol. Pharmacol. (Symp. Gastrointest. Hormones): 44.

Davison, J. S., and D. Grundy (1978) Modulation of single vaga! efferent fiber discharge by gastrointestinal afferents in the rat. J. Physiol. (Lond.) 284: 69-82.

Dodd, J., and J. S. Kelly (1981) The actions of cholecystokinin and related peptides on pyramidal neurons of the mammalian hippocampus. Brain Res. 205: 337-350.

Ewart, W. R., and D. L. Wingate (1983) Cholecystokinin octapeptide and gastric mechanoreceptor activity in the rat brain. Am. J. Physiol. 244: G613-G617.

Falasco, J. D., G. P. Smith, and J. Gibbs (1979) Cholecystokinin suppresses sham feeding in the rhesus monkey. Physiol. Behav. 23: 887-896.

Gibbs, J., R. C. Young, and G. P. Smith (1973) Cholecystokinin elicits satiety in rats with open gastric fistulas. Nature 245: 323--325.

Gibbs, J., J. D. Falasco, and P. R. McHugh (1976) Cholecystokinindecreased food intake in rhesus monkeys. Am. J. Physiol. 230: 1518.

Gonzalez, M. F., and J. A. Deutsch (1981) Vagotomy abolishes the cues of satiety produced by gastric distension. Science 212 : 12831284.

Harding, R, and B. F. Leek (1972) The effects of peripheral and central 
nervous influences on gastric center neuronal activity in sheep. $J$. Physiol. (Lond.) 225: 309-338.

Harding, R., and B. F. T eek (1973) Central projection of gastric afferent vagal inputs. J. Physiol. (Lond.) 228: 73-90.

Hommer, D. W., M. Palkovits, J. N. Crawley, S. M. Paul, and L. R. Skirboll (1985) Cholecystokinin-induced excitation in the substantia nigra: Evidence for peripheral and central components. J. Neurosci. 5: $1387-1392$.

Iggo, A. (1957) Gastrointestinal tension receptors with unmyelinated afferent fibers of the cat. Q. J. Exp. Physiol. 42: 130-143.

Jeftinija, S., V. Miletic, and M. Randic (1981) Cholecystokinin excites dorsal horn neurons both in vivo and in vitro. Brain Res. 213: 231236.

Kalia, M., and M. M. Mesulam (1980) Brainstem projections of sensory and motor components of the dorsal vagal complex in the cat: 2. Laryngeal, tracheobronchial, pulmonary, cardiac and gastrointestinal branches. J Comp. Neurol. 193: 467-508.

Kisselif, H. R., F. X. Pi-Sunyer, J. Thornton, J. Gibbs, and G. P. Smith (1979) Cholecystokinin-octapeptide (CCK8) decreases food intake in man. Am. J. Clin. Nutr. 32: 939.

Leek, B. F. (1969) Reticulo-ruminal mechanoreceptors in sheep. J. Physiol. (Lond.) 202: 585-609.

Leslie, R. A., D. G. Gwyn, and D. A. Hopkins (1982) The central distribution of the cervical vagus and gastric afferent and efferent projections in the rat. Brain Res. Bull. 8: 37-43.

Lorenz, D. N., and S. A. Goldman (1982) Vagal mediation of the cholecystokinin satiety effects in rats. Physiol. Behav. 29: 599-604.

Moran, T. H., and P. R. McHugh (1982) Cholecystokinin suppresses food intake by inhibiting gastric emptying. Am. J. Physiol. 242: R492R497.

Moran, T. H., G. P. Smith, A. M. Hostetler, and P. R. McHugh (1987) Transport of cholecystokinin (CCK) binding sites in subdiaphragmatic vagal branches. Brain Res. 415: 149-152.

Morin, W. P., P. dc Marchi, J. Champagnat, J. J. Vanderhacghan, J. Rossier, and M. Denavit-Saubie (1983) Inhibitory effect of cholecystokinin octapeptide on neurons in the nucleus tractus solitarius. Brain Res. 265: 333-338.

Morley, J. E., A. S. Levine, J. Kneip, and M. Grace (1982) The effect of vagotomy on the satiety effects of neuropeptides and naloxone. Life Sci. 30: 1943-1957.

Niijima, A. (1981) Visceral afferents and metabolic function. Diabetologica $20: 325-330$.

Oomura, J., M. Ohta, H. Kita, S. Ishibashi, and T. Okajami (1978) Hypothalamic neuron responses to glucose, phylorezin and cholecystokinin. In Iontophoretic and Transmitter Mechanisms in the Mammalian Central Nervous System, R. W. Ryall and J. S. Kelly, eds., pp. 120-123, Elsevier, New York.
Paintal, A. S. (1954) A study of gastric stretch receptors. Their role in the peripheral mechanism of satiation of hunger and thirst. J. Physiol. (Lond.) 126: 255-270.

Palkovits, M., and D. M. Jacobowitz (1974) Topographic atlas of catecholamine and acetylcholinesterase-containing neurons in the rat brain. 2. Hindbrain (mesencephalon, rhombencephalon). J. Comp. Neurol. 157: 29-42.

Raybould, H. E., R. J. Gayton, and G. J. Dockray (1985) CNS effects of circulating CCK8: Involvement of brainstem neurons responding to gastric distension. Brain Res. 342: 187-190.

Raybould, H. E., M. Roberts, and G. J. Dockray (1987) Reflex decrease in intragastric pressure in response to cholecystokinin in the rat. Am. J. Physiol. 253: 9165-9170.

Ritter, R. C., and E. E. Ladenheim (1985) Capsaicin pretreatment attenuates suppression of food intake by cholecystokinin. Am. J. Physiol. 248: R501-R504.

Rogers, R. C., and G. E. Hermann (1985) Gastric-vagal solitary neurons excited by paraventricular nucleus microstimulation. J. Autonom. Nerv. System 14: 351-362.

Scharoun, S. L., F. C. Barone, M. J. Wayner, and S. M. Jones (1984) Vagal and gastric connections to the central nervous system determined by the transport of horseradish peroxidase. Brain Res. Bull. 13: $575-583$.

Shapiro, R. E., and R. R. Miselis (1985) The central organization of the vagus nerve innervating the stomach of the rat. J. Comp. Neurol. 328: 478-488.

Smith, G. P., C. Jerome, B. J. Cushin, R. Eterno, and K. J. Simansky (1981) Afferent axons in the abdominal vagus mediate the satiety effect of cholecystokinin in the rat. Am. J. Physiol. 249: R638-R641.

Stacher, G. H., G. Steinringer, G. Schmierer, C. Schneider, and S. Winklehner (1982) Cholecystokinin octapeptide decreases intake of solid food in man. Peptides 3: 133-136.

Sturdevant, R. A. L., and H. Goetz (1976) Cholecystokinin both stimulates and inhibits human food intake. Nature 261: 713-715.

Wilbur, B. G., K. A. Kelly, and C. F. Code (1974) Effects of gastric fundectomy on canine gastric electrical and motor activity. Am. J. Physiol. 226: 1445-1449.

Zarbin, M. A., J. K. Walmsley, R. B. Innis, and M. J. Kuhar (1981) Cholecystokinin receptors: Presence and axonal flow in the rat vagus. Life Sci. 29: 697-705.

Zetler, G. (1980) Analgesia and ptosis caused by caerulein and cholecystokinin octapeptide. Neuropharmacology 19: 413-422.

Zetler, G. (1981) Anticonvulsant effects of caerulein and cholecystokinin octapeptide compared to those of diazepam. Eur. J. Pharmacol. 65: $297-300$. 